\title{
C-reactive protein in predicting major postoperative complications are there differences in open and minimally invasive colorectal surgery? Substudy from a randomized clinical trial
}

\author{
Jennifer Straatman ${ }^{1} \cdot$ Miguel A. Cuesta ${ }^{1}$ Jurriaan B. Tuynman ${ }^{1} \cdot$ Alexander A. F. A. Veenhof $^{2} \cdot$ Willem A. Bemelman $^{3}$. \\ Donald L. van der Peet ${ }^{1}$
}

Received: 26 November 2016 / Accepted: 2 December 2017 / Published online: 27 December 2017

(C) The Author(s) 2017. This article is an open access publication

\begin{abstract}
Background In search of improvement of patient assessment in the postoperative phase, C-reactive protein (CRP) is increasingly being studied as an early marker for postoperative complications following major abdominal surgery. Several studies reported an attenuated immune response in minimally invasive surgery, which might affect interpretation of postoperative CRP levels. The aim of the present study was to compare the value of CRP as a predictor for major postoperative complications in patients undergoing open versus laparoscopic colorectal surgery.

Methods A subgroup analysis from a randomized clinical trial (LAFA-trial) was performed, including all patients with nonmetastasized colorectal cancer. In the LAFA trial, patients were randomized to open or laparoscopic segmental colectomy. In a subgroup of 79 patients of the LAFA trial, postoperative assessment of CRP levels was conducted routinely preoperatively and $1,2,24$ and $72 \mathrm{~h}$ after surgery.

Results Thirty-seven patients were randomized to the open group and 42 patients to the laparoscopic group. Major complications occurred in $19 \%$ of laparoscopic procedures and $13.5 \%$ of open procedures $(p=0.776)$. CRP levels rise following surgical procedures. In uncomplicated cases, the rise in CRP levels was significantly lower at 24 and $72 \mathrm{~h}$ following laparoscopic resection in comparison to open resection. No differences in CRP levels were observed when comparing open and laparoscopic resection in patients with major complications.

Conclusion In patients with an uncomplicated postoperative course, CRP levels were lower following minimally invasive resection, possibly due to decreased operative trauma. No differences in CRP were observed stratified for surgical technique in patients with major complications. These results suggest that CRP may be applied as a marker for major postoperative complications in both open and minimally invasive colorectal surgery. Future research should aim to assess the role of standardized postoperative CRP measurements.
\end{abstract}

Keywords Minimally invasive surgery $\cdot$ Colorectal surgery $\cdot$ Postoperative complications $\cdot$ C-reactive protein $\cdot$ Quality control

Jennifer Straatman

je.straatman@vumc.nl

1 Department of Surgery, VU University Medical Center, De Boelelaan 1117 - ZH 7F020, 1081 HV Amsterdam, The Netherlands

2 Department of Surgery, Antoni van Leeuwenhoek Hospital, Amsterdam, The Netherlands

3 Department of Surgery, Academic Medical Center, Amsterdam, The Netherlands
Over the past decades, medical care for patients undergoing colorectal surgery has improved significantly with FastTrack perioperative care and minimally invasive surgical techniques [1]. Minimally invasive techniques have proven to be superior to conventional open techniques in colorectal surgery for short-term outcomes, such as improved postoperative recovery and a reduced postoperative systemic immune response with possible concomitant inhibitory effect on tumour spread and metastasis. Long-term outcomes are similar in both groups [2-18].

Major complications after colorectal surgery, requiring invasive treatment, are reported in up to $19 \%$ of patients [1, 
$19,20]$. In search of improvement of patient assessment in the postoperative phase, $\mathrm{C}$-reactive protein (CRP) is increasingly being studied as both an early marker for postoperative complications, as well as a safe discharge criterion [19,21]. CRP levels rise following surgery and a peak is observed after $48 \mathrm{~h}$. After $48 \mathrm{~h}$, levels decrease in patients with an uncomplicated postoperative course. CRP levels were found to be significantly higher in patients with major complications compared to patients with no or minor complications. These differences are observed from as early as the second postoperative day, with a median time from surgery to diagnosis of complications of 7 days [19]. Multiple studies have found CRP levels on the third and fourth postoperative day to be predictive for major complications following major abdominal surgery [21, 22].

Several studies have assessed the use of CRP as an early marker for postoperative complications following colorectal surgery. Some studies included both open and minimally invasive procedures, but no statistical analysis was performed on the differences between surgical techniques in these studies [23-28]. Several other studies included only open procedures $[29,30]$ or only minimally invasive procedures [31], with similar results.

If the inflammatory and immune responses are attenuated in minimally invasive procedures in comparison to open procedures, this might affect interpretation of postoperative CRP levels and could imply a different cut-off should be applied for CRP as a marker for complications [32]. A recent meta-analysis showed no differences in CRP levels between open and minimally invasive surgery in patients that suffered postoperative complications. The study did suffer from selection bias, since gastric and oesophageal resections were only performed with open procedures, whereas gastric bypass surgery was only performed laparoscopically [22]. Additional evidence is necessary.

The aim of the present study was to compare postoperative CRP levels in patients undergoing open versus laparoscopic colorectal surgery within the context of a randomized trial in which CRP was routinely measured.

\section{Materials and methods}

\section{Patients}

The here presented study was performed as an observational study from the LAFA trial, "Perioperative strategy in colonic surgery; LAparoscopy and/or FAst track multimodal management versus standard care". In the LAFA trial, patients were randomized to open or minimally invasive segmental colectomy and also randomized to standard or fast-track perioperative care. The full protocol was published previously [33]. Inclusion criteria consisted of (1) histologically confirmed malignancy or adenoma, (2) planned for elective segmental colectomy with curative intent, (3) age 40 to 80 years and (4) have an American Society of Anaesthesiologists (ASA) grade below IV. Exclusion criteria consisted of (1) a previous midline laparotomy, (2) emergency surgery, (3) planned ostomy or (4) immunosuppressive disease or medication. After obtaining informed consent, patients were randomized to open or minimally invasive elective segmental colectomy and fast-track or standard perioperative care. The design and primary results of the trial were previously published [1,34].

Patients operated in the VU university medical center and Academic medical center in Amsterdam, the Netherlands, were included in this subgroup analysis. Patients in these hospitals received standardized postoperative blood sampling. In other participating centres, standardized measurements were not possible due to logistical reasons (i.e. samples would not reach laboratory in set time period).

Recorded data regarding baseline characteristics included age, gender, BMI, co-morbidities and American College of Anaesthesiologists (ASA) classification. Recorded clinical parameters included indication for operation, type of surgery, duration of surgery, clinical parameters, performed CT-scans, complications according to Clavien-Dindo classification and mortality.

Complications were graded according to a modified Clavien-Dindo classification, which grades complications according to the necessitated treatment $[35,36]$. Minor complications, consisted of grade I and II, encompassing complications that require pharmacological treatment (i.e. antibiotics) and wound infections, treated by opening the wound at the bedside. Major complications consisted of grade III to $\mathrm{V}$, encompassing all complications that require invasive treatment (i.e. percutaneous drainage or reoperation), ICU admission and including those leading to death. Mortality was defined as in-hospital mortality.

All patients received perioperative prophylactic intravenous antibiotics and thromboprophylaxis according to local protocol. Treatments of major complications were classified as reoperations, radiological interventions such as percutaneous drainage and intensive care admission.

\section{Design}

Patients included in the LAFA-trial were randomized between laparoscopic or open segmental colectomy and fasttrack or standard postoperative care in a two by two balanced factorial design, using an online randomization tool. The study was conducted in accordance with the principles of the declaration of Helsinki and the protocol approved by local medical ethics review boards (protocol number: NTR222). All patients provided written informed consent prior to 
inclusion in the study. The full protocol of the study was previously published [1, 34].

Patients that were treated in the VU University medical center and Academic Medical Center in Amsterdam underwent additional measurements of CRP levels. Samples were collected routinely preoperatively and 1,2, 24 and $72 \mathrm{~h}$ after surgery. These measurements were planned alongside the original protocol and assessed and approved by the medical ethics committee. CRP data were compared for open and laparoscopic techniques. CRP samples were analysed by immunoturbidimetric methods, using the BM/Hitachi 705 (Boehringer, Mannheim, Germany).

All patients received similar postoperative assessment. Patients had daily assessment of clinical parameters (i.e. heart rate, blood pressure, temperature, pain, ileus). Upon clinical deterioration additional biochemical testing was performed (regardless of the standardized testing). Imaging was performed with computed tomography scans with oral and rectal contrast.

\section{Statistical analysis}

Statistical analysis was conducted in SPSS version 19.0 (SPSS Inc. Chicago, IL, USA). Continuous variables with normal distributions were presented as means and standard deviations. Medians and interquartile ranges were used as a central tendency for continuous variables with abnormal distributions. Categorical data were expressed with percentage frequencies. Comparison between the open and minimally invasive group was conducted with Student's $T$ test or Mann-Whitney-U as appropriate for continuous variables. Chi-square tests were used for comparison of categorical data. A value of $p<0.05$ was considered statistically significant. Logistic regression techniques were applied to determine confounders and effect-modifiers for major complications.

\section{Results}

Eighty-one patients were assessed for eligibility. For this study, two patients were excluded since they declined extra blood sampling due to needle-phobia. Seventy-nine patients were randomized. Thirty-seven patients were randomized to an open procedure and 42 patients were randomized to a laparoscopic procedure in a $2 \times 2$ factorial design. The original trial also randomized patients to standard or fast-track perioperative care. In the laparoscopic group, 19 patients were randomized to fast-track care and 23 patients were randomized to standard care. In the open group, 17 patients received Fast Track care and 20 patients received standard care.
A flow chart for patient inclusion is depicted in Fig. 1. Baseline characteristics are depicted in Table 1. No statistically significant differences were observed between the open and laparoscopic group for patient characteristics. $94.7 \%$ of samples were collected and analysed on time, taking into account accrual times as described in the study protocol. Missing values were mainly caused by delay; samples were dismissed if they arrived at the laboratory outside the predetermined time interval. These samples were not analysed, and not included in the analysis for that measurement. (i.e. four patients excluded for analysis of 72-h samples).

\section{Surgical procedures}

All patients underwent elective segmental colectomy for cancer. No significant differences were observed for the frequency of performed type of colectomy in the open or minimally invasive group (i.e. sigmoid resection, right or left hemicolectomy). Duration of surgery was significantly longer and blood loss was significantly less in the laparoscopy group $(p<0.001)$. In one patient, the procedure was converted to an open colectomy because of bulky tumour with ingrowth in the abdominal wall. Analysis was performed according to the intention to treat principle and this patient was analysed in the laparoscopy group.

\section{Postoperative complications}

Complications were observed in $27.8 \%$ of patients. Major complications were observed in eight laparoscopy patients (19.1\%) and in five patients who underwent an open procedure (13.5\%). Minor complications were observed in 11.9\% of laparoscopic procedures and $10.8 \%$ of open procedures. No differences in complication rates were observed for open and laparoscopic procedures ( $p=0.540$ for minor complications, $p=0.351$ for major complications).

An overview of complications is depicted in Table 2. In patients with an uncomplicated postoperative course, following both open and minimally invasive procedures, hospital stay was significantly shorter in comparison to patients with a complicated postoperative course. Hospital stay was significantly longer in complicated patients and did not differ between open and laparoscopic procedures, as depicted in Table 1.

\section{C-reactive protein}

CRP data were collected routinely preoperatively (baseline) and 1,2, 24 and $72 \mathrm{~h}$ postoperatively. No differences in CRP levels were observed between the different postoperative care groups, being standard versus fast track care, and minimally invasive versus open procedures, with a median CRP at $72 \mathrm{~h}$ of 124 in the standard care group 


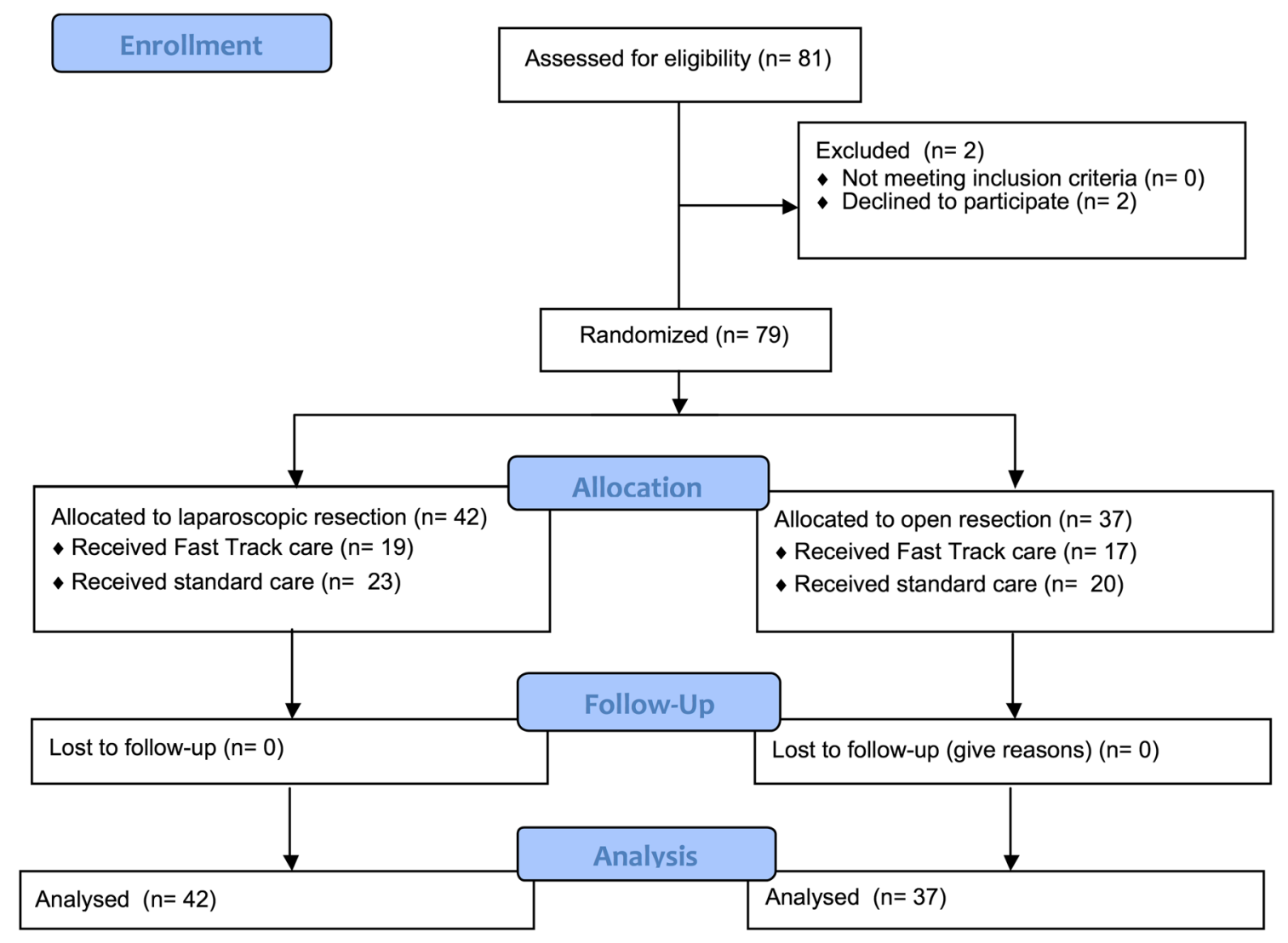

Fig. 1 Flow chart for inclusion and analysis of patients

and 96 in the fast-track group $(p=0.137)$. CRP levels measured after diagnosis of a complication were excluded (Table 3).

Data were stratified for patients with major complications in comparison to patients with no or minor complications, as depicted in Fig. 2. In concordance with previous analyses, CRP levels were significantly lower in patients who underwent a laparoscopic procedure. At $24 \mathrm{~h}$ postoperatively median CRP levels were $164 \mathrm{mg} / \mathrm{L}$ in the open group versus $99 \mathrm{mg} / \mathrm{L}$ in the minimally invasive group $(p=0.008)$.

Analysis was further stratified for postoperative complications, comparing patients with major complications to patients with no or minor complications. In patients who had no or minor complications, CRP levels were lower in patients who underwent a minimally invasive procedure compared to open procedures at 24 and $72 \mathrm{~h}$ after surgery $(p<0.05)$. Receiver operator characteristic ROC curve analysis for CRP levels $72 \mathrm{~h}$ postoperatively as a marker for major complications revealed an area under the curve of 0.674 (95\% confidence interval 0.506-0.842). By determining the Youden-index, the optimal cut-off was determined at CRP levels of $140 \mathrm{mg} / \mathrm{L}$ at $72 \mathrm{~h}$ postoperatively, with a negative predictive value of $90.2 \%$ and positive predictive value of $36.4 \%$.

\section{Logistic regression analysis}

Backward stepwise regression analysis was performed, to assess predictors for major complications. The following parameters were assessed in the model: laparoscopic versus open surgery, CRP levels $72 \mathrm{~h}$ postoperatively, sex, age and ASA-classification. The model is depicted in Table 4. In the primary multivariate regression model, with 5 variables in the equation, CRP levels at $72 \mathrm{~h}$ were not predictive for major complications. Following backward stepwise logistic regression, with a cut-off at $p=0.1$, only CRP levels $72 \mathrm{~h}$ after surgery were found to be a significant predictor for major postoperative complications.

\section{Discussion}

Regardless of the applied surgical techniques, open or minimally invasive colorectal resection, postoperative CRP levels can be used to predict or rule out major postoperative complications.

In this subgroup analysis of a randomized clinical trial comparing open and minimally invasive surgery for colorectal cancer, CRP levels in patients with an uncomplicated 
Table 1 Baseline characteristics

\begin{tabular}{|c|c|c|c|}
\hline Parameter & Open & Minimally invasive & $p$ value \\
\hline Patients $(n)$ & 37 & 42 & \\
\hline Gender male (\%) & $26(69 \%)$ & $23(62.2 \%)$ & 0.52 \\
\hline Age years $($ mean $\pm S D)$ & $66.3 \pm 12$ & $66.7 \pm 9.7$ & 0.86 \\
\hline Body mass index (BMI) mean \pm SD & $25.8 \pm 4.3$ & $25.3 \pm 3.3$ & 0.59 \\
\hline \multicolumn{4}{|l|}{ ASA-classification } \\
\hline I & $9(24.3 \%)$ & $14(33.3 \%)$ & \multirow[t]{4}{*}{0.50} \\
\hline II & $24(56.8 \%)$ & $24(57.2 \%)$ & \\
\hline III & $6(16.2 \%)$ & $4(9.5 \%)$ & \\
\hline IV & $1(2.7 \%)$ & 0 & \\
\hline Comorbid disorders & $27(73 \%)$ & $29(69 \%)$ & 0.70 \\
\hline \multicolumn{4}{|l|}{ Operative details } \\
\hline \multicolumn{4}{|l|}{ Surgery type } \\
\hline Right hemicolectomy & $20(54.1 \%)$ & $15(35.7 \%)$ & \multirow[t]{5}{*}{0.47} \\
\hline Transverse colectomy & $1(2.7 \%)$ & $3(7.1 \%)$ & \\
\hline Left hemicolectomy & $3^{\mathrm{a}}(8.1 \%)$ & $5(11.9 \%)$ & \\
\hline Sigmoid resection & $11(29.7 \%)$ & $14(33.3 \%)$ & \\
\hline Rectum resection & $2(5.4 \%)$ & $5(11.9 \%)$ & \\
\hline Duration of surgery min $($ mean $\pm S D)$ & $130(98-173)$ & $191(160-220)$ & $<0.001$ \\
\hline Blood loss & $230(150-400)$ & $80(0-150)$ & $<0.001$ \\
\hline \multicolumn{4}{|l|}{ Postoperative complications } \\
\hline Uncomplicated $^{\mathrm{a}}$ & $28(75.7 \%)$ & $29(69 \%)$ & 0.47 \\
\hline Minor complication & $4(10.8 \%)$ & $5(11.9 \%)$ & 0.78 \\
\hline Major complication & $5(13.5 \%)$ & $8(19.1 \%)$ & 0.51 \\
\hline \multicolumn{4}{|l|}{ Hospital stay [median days (IQR)] } \\
\hline Uncomplicated & $6(4-9)$ & $4(3-7)$ & 0.01 \\
\hline Minor complication & $10(8-19)$ & $14(7-16)$ & 0.99 \\
\hline Major complication & $18(11-72)$ & $23(13-40)$ & 0.94 \\
\hline 30-day mortality & 1 & - & 0.29 \\
\hline
\end{tabular}

Student's $T$ test was applied if the mean and standard deviation (SD) are depicted, being normal distributions. Mann-Whitney- $U$ tests were applied if median and interquartile ranges (IQR) are depicted, being non-normal distributions

ASA American Society of Anaesthesiologists

${ }^{\mathrm{a}}$ Chi-square test with post hoc Bonferroni analysis

postoperative course or minor complication were significantly lower in the minimally invasive group compared to the open group at 24 and $72 \mathrm{~h}$ postoperatively, whereas in patients with major complications no differences were observed for CRP levels between the two different surgical approaches. Correction with backward logistic regression techniques further emphasized that there was no effectmodification or confounding by surgical approach in the relationship between CRP levels and major postoperative complications. The determined cut-off for CRP as a marker for major postoperative complications was similar to a previously determined optimal cut-off based on a pooled analysis of 1427 patients, and the cut-off can be applied in both open and laparoscopic segmental colectomy [21].

The logistic regression model shows CRP levels at $72 \mathrm{~h}$ postoperatively to be predictive of postoperative complications. It should be noted the calculated AUC of 0.674 is lower compared to other similar studies [26], and may be explained by the smaller cohort size. In the primary multivariate regression model, CRP levels at $72 \mathrm{~h}$ were not predictive for major complications. This may be caused by having too many variables in the equation and low number of patients with major complications, giving a low sample size per variable. In a recent meta-analysis, including 1427 patients, CRP levels on the third postoperative day where found to be predictive for major complications with an AUC of 0.789 , further supporting the use of CRP measurements as a tool for early detection of patients at risk of developing major complications [21].

CRP is a well-established marker for inflammation and has been studied as a predictor of postoperative complications; CRP was assessed separately as (1) a marker for 
Table 2 Overview of all postoperative complications

\begin{tabular}{|c|c|c|c|c|c|}
\hline Complication & Open & $\%$ & $\begin{array}{l}\text { Mini- } \\
\text { mally } \\
\text { invasive }\end{array}$ & $\%$ & $p$ value \\
\hline Patients $(n)$ & 37 & & 42 & & \\
\hline Anastomotic leak & 3 & 8.1 & 3 & 7.1 & 0.87 \\
\hline Surgery & 2 & & 1 & & \\
\hline Percutaneous drainage & 1 & & 2 & & \\
\hline Prolonged postoperative ileus & 2 & 5.4 & 6 & 14.3 & 0.19 \\
\hline Surgery & - & & 3 & & \\
\hline Wound/stoma problem & 3 & 8.1 & 2 & 2.5 & 0.54 \\
\hline Surgery & - & & - & & \\
\hline \multicolumn{6}{|l|}{ Non-abdominal } \\
\hline Pneumonia & 2 & 5.4 & 2 & 4.8 & 0.90 \\
\hline Cardiac complications & 2 & 5.4 & 2 & 4.8 & 0.90 \\
\hline
\end{tabular}

Cardiac complications occurred after the fifth postoperative day in both affected patients anastomotic leak, (2) a marker for major complications and (3) a marker for all postoperative complications. Interestingly, multiple studies that assessed postoperative CRP levels included patients that were operated using both minimally invasive approach as well as conventional open approach. In these studies, no separate analysis was performed for differences in CRP levels between open and minimally invasive techniques [23-26, 37-39]. Only one study assessed both surgical techniques separately and found that average CRP levels were lower following minimally invasive surgery compared to open surgery, although the data were not stratified for adverse events [40]. Another study assessed CRP levels including only patients that underwent minimally invasive colorectal surgery and found a cut-off of $200 \mathrm{mg} / \mathrm{L}$ on postoperative day 3 as marker for major complications [31]. These results are similar to the study here presented. CRP levels at $72 \mathrm{~h}$ postoperatively were found to be predictive of major complications in patients that underwent open and minimally invasive surgery for colorectal cancer.

The results of the study here presented underpin the use of postoperative CRP levels as a marker for complications,

Table 3 Median CRP values and interquartile ranges in open and minimally invasive surgery

\begin{tabular}{|c|c|c|c|c|c|c|}
\hline \multirow[t]{3}{*}{ CRP } & \multicolumn{6}{|l|}{ Open } \\
\hline & \multicolumn{2}{|l|}{ Overall } & \multicolumn{2}{|c|}{ Uncomplicated } & \multicolumn{2}{|c|}{ Major complication } \\
\hline & CRP (mg/L) & IQR & $\mathrm{CRP}(\mathrm{mg} / \mathrm{L})$ & IQR & CRP (mg/L) & IQR \\
\hline Preop & 4 & $3-10$ & 3 & $3-9$ & 4 & $2-11$ \\
\hline $1 \mathrm{~h}$ & 7 & $3-13$ & 10 & $3-15$ & 3 & $2-11$ \\
\hline $2 \mathrm{~h}$ & 4 & $3-13$ & 5 & $3-16$ & 3 & $2-11$ \\
\hline $24 \mathrm{~h}$ & 164 & $102-200$ & 158 & $92-207$ & 171 & $133-198$ \\
\hline $72 \mathrm{~h}$ & 126 & $94-170$ & 123 & $89-153$ & 170 & $138-229$ \\
\hline \multirow[t]{3}{*}{ CRP } & \multicolumn{6}{|c|}{ Minimally invasive } \\
\hline & \multicolumn{2}{|l|}{ Overall } & \multicolumn{2}{|c|}{ Uncomplicated } & \multicolumn{2}{|c|}{ Major complication } \\
\hline & $\mathrm{CRP}(\mathrm{mg} / \mathrm{L})$ & IQR & $\mathrm{CRP}(\mathrm{mg} / \mathrm{L})$ & IQR & CRP (mg/L) & IQR \\
\hline Preop & 3 & $3-17$ & 3 & $2-19$ & 3 & $2-17$ \\
\hline $1 \mathrm{~h}$ & 3 & $3-15$ & 3 & $2-19$ & 3 & $2-11$ \\
\hline $2 \mathrm{~h}$ & 3 & $3-17$ & 4 & $3-22$ & 3 & $2-14$ \\
\hline $24 \mathrm{~h}$ & 99 & $53-166$ & 96 & $46-152$ & 137 & $3-190$ \\
\hline $72 \mathrm{~h}$ & 84 & $43-152$ & 78 & $32-138$ & 125 & $56-430$ \\
\hline \multirow[t]{3}{*}{ CRP } & & & \multicolumn{4}{|c|}{ Open versus minimally invasive colorectal resection } \\
\hline & & & Uncomplicated & & & $\begin{array}{l}\text { Major } \\
\text { complica- } \\
\text { tions }\end{array}$ \\
\hline & & & $p$ value & & & $p$ value \\
\hline Preop & & & 0.89 & & & 1.00 \\
\hline $1 \mathrm{~h}$ & & & 0.31 & & & 0.88 \\
\hline $2 \mathrm{~h}$ & & & 0.35 & & & 0.83 \\
\hline $24 \mathrm{~h}$ & & & 0.01 & & & 0.64 \\
\hline $72 \mathrm{~h}$ & & & 0.05 & & & 0.52 \\
\hline
\end{tabular}

Significant differences are highlighted in bold 
Fig. 2 Postoperative median CRP levels in patients operated with minimally invasive or open techniques, stratified for major complications. Row A depicts $p$ values for differences between open and minimally invasive surgery in patients with an uncomplicated or minor complicated postoperative course. Row $\mathrm{B}$ depicts $p$ values in patients with major complications. $p$ values were calculated using Mann-Whitney- $U$ tests

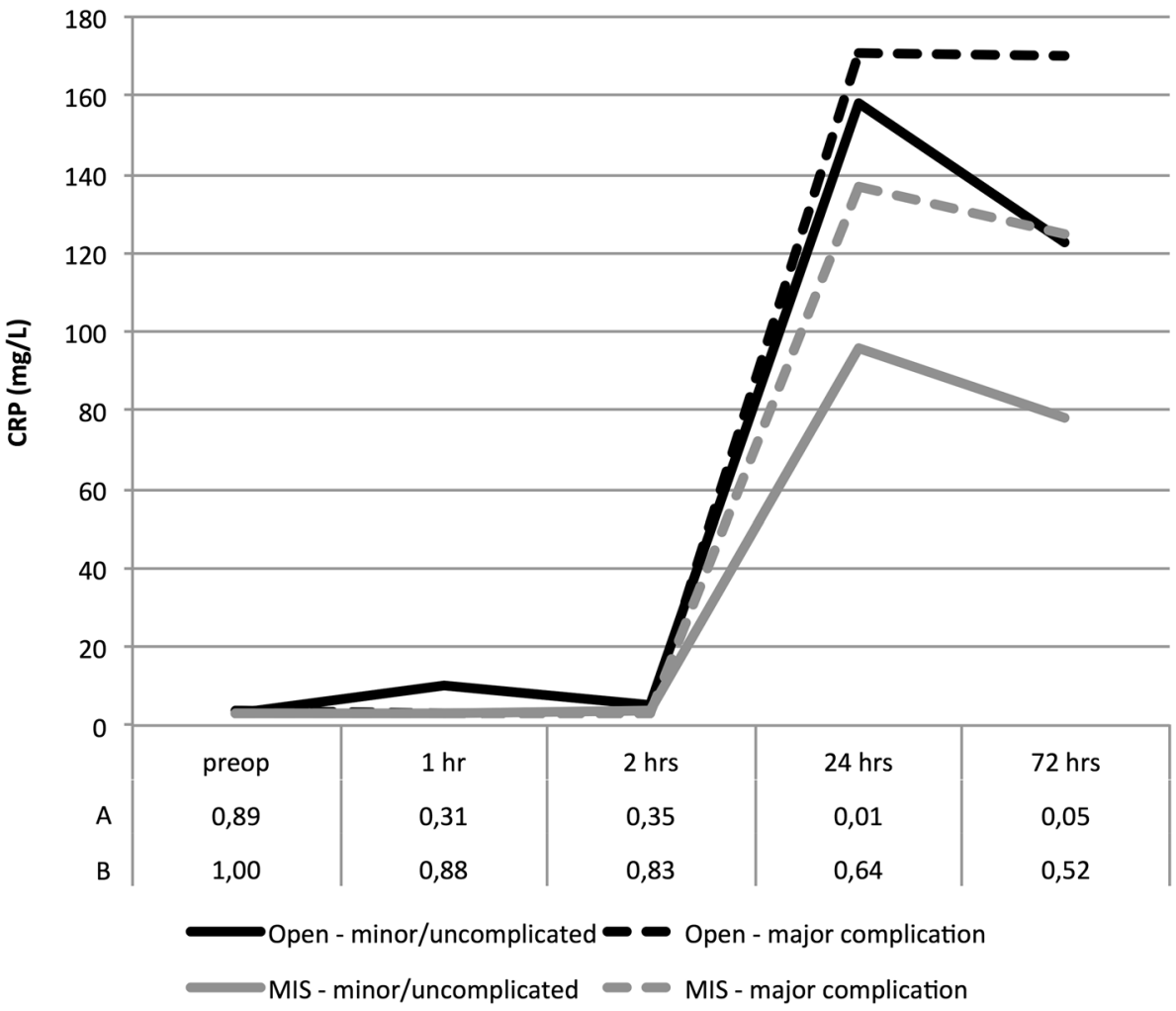

Table 4 Logistic regression analysis for major complications

\begin{tabular}{lllll}
\hline Variables in the equation & B & S.E. & $p$ value & Exp (B) \\
\hline 3a: Primary model & & & & \\
Access: open versus lapa- & -0.391 & 1.082 & 0.718 & 0.677 \\
$\quad$ roscopy & & & & \\
CRP 72 h & 0.001 & 0.004 & 0.758 & 1.001 \\
CRP 72 h by access & 0.005 & 0.006 & 0.33 & 1.005 \\
Female sex & -0.212 & 0.796 & 0.79 & 0.809 \\
ASA class I & Ref. & & 0.862 & \\
ASA class II & -0.597 & 0.909 & 0.511 & 0.55 \\
ASA class III & -1.288 & 1.541 & 0.403 & 0.276 \\
ASA class IV & 22.2 & 40,192 & 0.999 & $4,414,812$ \\
Age & 0.032 & 0.004 & 0.758 & 1.032 \\
Constant & -3.384 & 3.345 & 0.312 & 0.034 \\
3b: Final model & & & & \\
CRP 72 h & 0.004 & 0.002 & 0.05 & 1.004 \\
Constant & -2.173 & 0.48 & 0.001 & 0.114 \\
\hline
\end{tabular}

In the primary model, all variables were inserted. Following backward stepwise regression analysis CRP remained as only significant predictor for major complications, with the overall model $p<0.05$

CRP was added in the model per increase of 1 point in CRP levels. i.e. a $10 \mathrm{mg} / \mathrm{mL}$ point rise in CRP levels would be an odds radio of 1.04

regardless of surgical approach. The results further indicate that major complications may be developing earlier than we think. Higher CRP levels are seen in patients with major complications in comparison to patients with no or minor complications at $72 \mathrm{~h}$ postoperatively, whereas average time to diagnosis of complications is currently 5 days. A recent meta-analysis supports our findings; CRP levels were lower in patients that underwent minimally invasive surgery compared to open surgery if no complications occurred. As stated in the introduction this study suffered from selection bias [37]. Hence, we present this study based on randomized data.

Differences in CRP levels between open and minimally invasive surgery in patients with an uncomplicated or minor complicated postoperative course can be explained by the differences in the amount of operative trauma, leading to lower levels of acute phase proteins such as CRP and interleukin-6 [27, 41].

In patients with an uncomplicated postoperative course surgical trauma is the only stimulus for CRP synthesis. In patients with postoperative complications both surgical trauma and complications add up to increase CRP synthesis. Since no differences were observed in CRP levels between open or minimally invasive colorectal resection in patients with a postoperative complication, it is hypothesized that complications have a greater effect on CRP synthesis than surgical trauma, thereby diminishing the differences seen in uncomplicated patients.

This study was performed as a sub-study of the LAFAtrial, which investigated differences between both laparoscopic or open segmental colectomy and fast-track or 
standard care. The study has several limitations. Selection bias may not be omitted; since standardized measurements were performed only in two participating centers, these patients were included in this subgroup analysis. With standardized measurements only being available from two centers, the sample size is small.

The study was limited by its observational nature. CRP levels were measured routinely. In many observational studies, CRP levels are only determined on demand. A prospective clinical trial is underway from our department in order to further assess the role of standardized CRP measurements in a postoperative quality control algorithm for prediction of complications and as a safe discharge criterion [42].

In conclusion, CRP may be used as a marker for major postoperative complications in both open and minimally invasive colorectal surgery. Lower postoperative CRP levels are seen in patients who underwent minimally invasive surgery with an uncomplicated postoperative course and patients with minor postoperative complications, possibly due to a reduced amount of surgical trauma in minimally invasive surgery compared to open surgery. The inflammatory response in major complications is believed to exceed the effect of primary surgical trauma, and no differences in CRP levels are observed between open or minimally invasive surgery for colorectal cancer. Future research should aim to assess the role of standardized CRP measurements in patients undergoing major abdominal surgery.

Author contributions DvdP, MC, AV and WB designed the study. JS, JB and AV collected data. JS analysed the data. JS, WB, DvP and MC drafted the manuscript. JB and AV critically revised the manuscript. All authors approved the final version of the manuscript.

\section{Compliance with ethical standards}

Disclosures Jennifer Straatman, Miguel A. Cuesta, Jurriaan B. Tuynman, Alexander F. A. A. Veenfhof, Willem A. Bemelman and Donald L. van der Peet declare no conflicts of interest or financial ties to disclose.

Open Access This article is distributed under the terms of the Creative Commons Attribution 4.0 International License (http://creativecommons.org/licenses/by/4.0/), which permits unrestricted use, distribution, and reproduction in any medium, provided you give appropriate credit to the original author(s) and the source, provide a link to the Creative Commons license, and indicate if changes were made.

\section{References}

1. Vlug MS, Wind J, Hollmann MW, Ubbink DT, Cense HA, Engel AF, Gerhards MF, van Wagensveld BA, van der Zaag ES, van Geloven AAW, Sprangers MAG, Cuesta MA, Bemelman WA (2011) Laparoscopy in combination with Fast Track Multimodal Management is the best perioperative strategy in patients undergoing colonic surgery (LAFA-study). Ann Surg 254:868-875
2. Nason GJ, Barry BD, Obinwa O, McMacken E, Rajaretnam NS, Neary PC (2014) Early rise in C-reactive protein is a marker for infective complications in laparoscopic colorectal surgery. Surg Laparosc Percutaneous Techn 24:57-61

3. Lacy AM, Delgado S, Castells A, Prins HA, Arroyo V, Ibarzabal A, Pique JM (2008) The long-term results of a randomized clinical trial of laparoscopy-assisted versus open surgery for colon cancer. Ann Surg 248:1-7

4. Boni L, Benevento A, Rovera F, Dionigi G, Di Giuseppe M, Bertoglio C, Dionigi R (2006) Infective complications in laparoscopic surgery. Surg Infect 7(Suppl 2):S109-S111

5. Kavanagh DO, Gibson D, Moran DC, Smith M, K OD, Eguare E, Keane FB, DS OR, Neary PC (2011) Short-term outcomes following laparoscopic resection for colon cancer. Int J Colorectal Disease 26:361-368

6. Wang G, Jiang Z, Zhao K, Li G, Liu F, Pan H, Li J (2012) Immunologic response after laparoscopic colon cancer operation within an enhanced recovery program. J Gastrointest Surg: Official J Soc Surg Aliment Tract 16:1379-1388

7. Reza MM, Blasco JA, Andradas E, Cantero R, Mayol J (2006) Systematic review of laparoscopic versus open surgery for colorectal cancer. Br J Surg 93:921-928

8. Leung KL, Kwok SP, Lam SC, Lee JF, Yiu RY, Ng SS, Lai PB, Lau WY (2004) Laparoscopic resection of rectosigmoid carcinoma: prospective randomised trial. Lancet 363:1187-1192

9. Ordemann J, Jacobi CA, Schwenk W, Stosslein R, Muller JM (2001) Cellular and humoral inflammatory response after laparoscopic and conventional colorectal resections. Surg Endosc 15:600-608

10. Noel JK, Fahrbach K, Estok R, Cella C, Frame D, Linz H, Cima RR, Dozois EJ, Senagore AJ (2007) Minimally invasive colorectal resection outcomes: short-term comparison with open procedures. J Am Coll Surg 204:291-307

11. Abraham NS, Young JM, Solomon MJ (2004) Meta-analysis of short-term outcomes after laparoscopic resection for colorectal cancer. Br J Surg 91:1111-1124

12. Hildebrandt U, Kessler K, Plusczyk T, Pistorius G, Vollmar B, Menger MD (2003) Comparison of surgical stress between laparoscopic and open colonic resections. Surg Endosc 17:242-246

13. Kohli R, Bansal E, Gupta AK, Matreja PS, Kaur K (2014) To study the levels of C-reactive protein and total leucocyte count in patients operated of open and laparoscopic cholecystectomy. $\mathbf{J}$ Clin Diagn Res: JCDR 8:NC06-NC08

14. Ramanathan ML, MacKay G, Platt J, Horgan PG, McMillan DC (2014) The impact of open versus laparoscopic resection for colon cancer on C-reactive protein concentrations as a predictor of postoperative infective complications. Ann Surg Oncol

15. Okholm C, Goetze JP, Svendsen LB, Achiam MP (2014) Inflammatory response in laparoscopic vs. open surgery for gastric cancer. Scand J Gastroenterol 49:1027-1034

16. Hirokawa F, Hayashi M, Miyamoto Y, Asakuma M, Shimizu T, Komeda K, Inoue Y, Uchiyama K (2015) Short- and long-term outcomes of laparoscopic versus open hepatectomy for small malignant liver tumors: a single-center experience. Surg Endosc 29:458-465

17. Bulut O, Aslak KK, Levic K, Nielsen CB, Romer E, Sorensen S, Christensen IJ, Nielsen HJ (2015) A randomized pilot study on single-port versus conventional laparoscopic rectal surgery: effects on postoperative pain and the stress response to surgery. Techn Coloproctol 19:11-22

18. Kvarnstrom A, Swartling T, Kurlberg G, Bengtson JP, Bengtsson A (2013) Pro-inflammatory cytokine release in rectal surgery: comparison between laparoscopic and open surgical techniques. Archivum immunologiae et therapiae experimentalis 61:407-411

19. Straatman J, Cuesta MA, Gisbertz SS, van der Peet DL (2014) Value of a step-up diagnosis plan: CRP and CT-scan to diagnose 
and manage postoperative complications after major abdominal surgery. Rev Esp Enferm Dig 106:515-521

20. van der Pas MH, Haglind E, Cuesta MA, Fürst A, Lacy AM, Hop WC, Bonjer HJ (2013) Laparoscopic versus open surgery for rectal cancer (COLOR II): short-term outcomes of a randomised, phase 3 trial. Lancet 14:210-218

21. Straatman J, Harmsen AM, Cuesta MA, Berkhof J, Jansma EP, van der Peet DL (2015) Predictive value of C-reactive protein for major complications after major abdominal surgery: a systematic review and pooled-analysis. PLoS ONE 10:e0132995

22. Adamina M, Steffen T, Tarantino I, Beutner U, Schmied BM, Warschkow R (2015) Meta-analysis of the predictive value of $\mathrm{C}$-reactive protein for infectious complications in abdominal surgery. Brit J Surg 102:590-598

23. Kørner H, Nielsen HJ, Søreide JA, Nedrebø BS, Søreide K, Knapp JC (2009) Diagnostic accuracy of C-reactive protein for intraabdominal infections after colorectal resections. J Gastrointest Surg: Official J Soc Surg Aliment Tract 13:1599-1606

24. MacKay GJ, Molloy RG, O'Dwyer PJ (2011) C-reactive protein as a predictor of postoperative infective complications following elective colorectal resection. Colorectal Dis: Official J Assoc Coloproctol G B Irel 13:583-587

25. Ortega-Deballon P, Radais F, Facy O, d'Athis P, Masson D, Charles PE, Cheynel N, Favre JP, Rat P (2010) C-reactive protein is an early predictor of septic complications after elective colorectal surgery. World J Surg 34:808-814

26. Garcia-Granero A, Frasson M, Flor-Lorente B, Blanco F, Puga R, Carratala A, Garcia-Granero E (2013) Procalcitonin and C-reactive protein as early predictors of anastomotic leak in colorectal surgery: a prospective observational study. Dis Colon Rectum 56:475-483

27. Veenhof AA, Vlug MS, van der Pas MH, Sietses C, van der Peet DL, de Lange-de Klerk ES, Bonjer HJ, Bemelman WA, Cuesta MA (2012) Surgical stress response and postoperative immune function after laparoscopy or open surgery with fast track or standard perioperative care: a randomized trial. Ann Surg 255:216-221

28. Wu FP, Hoekman K, Sietses C, von Blomberg BM, Meijer S, Bonjer HJ, Cuesta MA (2004) Systemic and peritoneal angiogenic response after laparoscopic or conventional colon resection in cancer patients: a prospective, randomized trial. Dis Colon Rectum 47:1670-1674

29. Welsch T, Müller SA, Ulrich A, Kischlat A, Hinz U, Kienle P, Büchler MW, Schmidt J, Schmied BM (2007) C-reactice protein as early predictor for infectious complications in rectal surgery. Int J Colorectal Dis 22:1499-1507

30. Warschkow R, Tarantino I, Torzewski M, Näf F, Lange J, Steffen T (2011) Diagnostic accuracy of C-reactive protein and white blood cell counts in the early detection of inflammatory complications after open resection of colorectal cancer: a retrospective study of 1187 patients. Int J Colorectal Dis 26:1405-1413

31. Pedersen T, Roikjær O, Jess P (2012) Increased levels of $\mathrm{C}$-reactive protein and leukocyte count are poor predictors of anastomotic leakage following laparoscopic colorectal resection. Dan Med J 59:e1-e4

32. Sietses C, Beelen RH, Meijer S, Cuesta MA (1999) Immunological consequences of laparoscopic surgery, speculations on the cause and clinical implications. Langenbecks Arch Surg 384:250-258

33. Wind J, Hofland J, Preckel B, Hollmann MW, Bossuyt PM, Gouma DJ, van Berge Henegouwen MI, Fuhring JW, Dejong $\mathrm{CH}$, van Dam RM, Cuesta MA, Noordhuis A, de Jong D, van Zalingen E, Engel AF, Goei TH, de Stoppelaar IE, van Tets WF, van Wagensveld BA, Swart A, van den Elsen MJ, Gerhards MF, de Wit LT, Siepel MA, van Geloven AA, Juttmann JW, Clevers W, Bemelman WA (2006) Perioperative strategy in colonic surgery; LAparoscopy and/or FAst track multimodal management versus standard care (LAFA trial). BMC Surg 6:16

34. Wind JHJ, Preckel B, Hollmann MW et al. (2006) Perioperative strategy in colonic surgery; LAparoscopy and/or FAst track multimodal management versus standard care (LAFA trial). BMC Surg 6:51

35. Clavien PA, Barkun J, de Oliveira ML, Vauthey JN, Dindo D, Schulick RD, de Santibañes E, Pekolj J, Slankamenac K, Bassi C, Graf R, Vonlanthen R, Padbury R, Cameron JL, Makuuchi M (2009) The Clavien-Dindo classification of surgical complications; five year experience. Ann Surg 250:187-196

36. Dindo D, Demartines N, Clavien PA (2004) Classification of surgical complications; a new proposal with evaluation in a cohort of 6336 patient and results of a survey. Ann Surg 240:205-213

37. Adamina M, Warschkow R, Naf F, Hummel B, Rduch T, Lange J, Steffen T (2014) Monitoring c-reactive protein after laparoscopic colorectal surgery excludes infectious complications and allows for safe and early discharge. Surg Endosc 28:2939-2948

38. Oberhofer D, Juras J, Pavičic AM, Žuric IR, Rumenjak V (2012) Comparison of C-reactive protein and procalcitonin as predictors of postoperative infectious complications after elective colorectal surgery. Croat Med J 53:612-619

39. Platt JJ, Ramanathan ML, Crosbie RA, Anderson JH, McKee RF, Horgan PG, McMillan DC (2012) C-reactive protein as a predictor of postoperative infective complications after curative resection in patients with colorectal cancer. Ann Surg Oncol 19:4168-4177

40. Lane JC, Wright S, Burch J, Kennedy H, Jenkins JT (2012) Early prediction of adverse events in enhanced recovery based upon the host systemic inflammatory response. Colorectal Dis 15:224-230

41. Watt DG, Horgan PG, McMillan DC (2015) Routine clinical markers of the magnitude of the systemic inflammatory response after elective operation: a systematic review. Surgery 157:362-380

42. Straatman J, Cuesta MA, Schreurs WH, Dwars BJ, Cense HA, Rijna H, Sonneveld DJA, den Boer FC, de, van der Peet DL, Lange-de Klerk ES (2015) The PRECious trial PREdiction of complications, a step-up approach, CRP first followed by CT-scan imaging to ensure quality control after major abdominal surgery: study protocol for a stepped-wedge trial. Trials $16: 382$ 